\title{
Chapter 4 \\ Experiences After 5 Years of AiREAS and 1 Year of ILM
}

\author{
Jean-Paul Close, Sandra van der Sterren, Marco van Lochem, \\ René Otjes and Mary-Ann Schreurs
}

\subsection{The Way Things Work at AiREAS}

The process of figuring out the way things would work at AiREAS had been completed in one initial loop, referred to as the STIR loop. This means that, from an empty table and a shared higher purpose, a wellbeing-based, human values-structured project produced measureable results that could be expanded across the world through welfare-based economies. The loop added unique new values to the community. These values enhance the potential sustainable human progression through steps towards better air quality and health while each has an economic potential on the world market through expansion. A new economy and economic model arises and proves itself upon closure of this loop. It became an example for the world of how trade- and growth-oriented structures could engage in wellness based commitment trusting that elements would appear that enhanced their global competitive positioning. This is what makes this exercise so unique and interesting, much more than the simple design of a technological measurement system (Fig. 4.1).

During the AiREAS general members meeting of January 2014, this working model was the one that elicited the most praise and came to be considered one of the key values of AiREAS for expansion worldwide. By that time, the members and participants had had a lot of experience with the model. This has been captured in

J.-P. Close $(\bowtie)$

STIR Foundation, Eindhoven, The Netherlands

S. van der Sterren · M.-A. Schreurs

Department of Environment-Air Quality, Eindhoven, The Netherlands

M. van Lochem

Axians, Eindhoven, The Netherlands

R. Otjes

ECN, Petten, The Netherlands

(C) The Author(s) 2016 


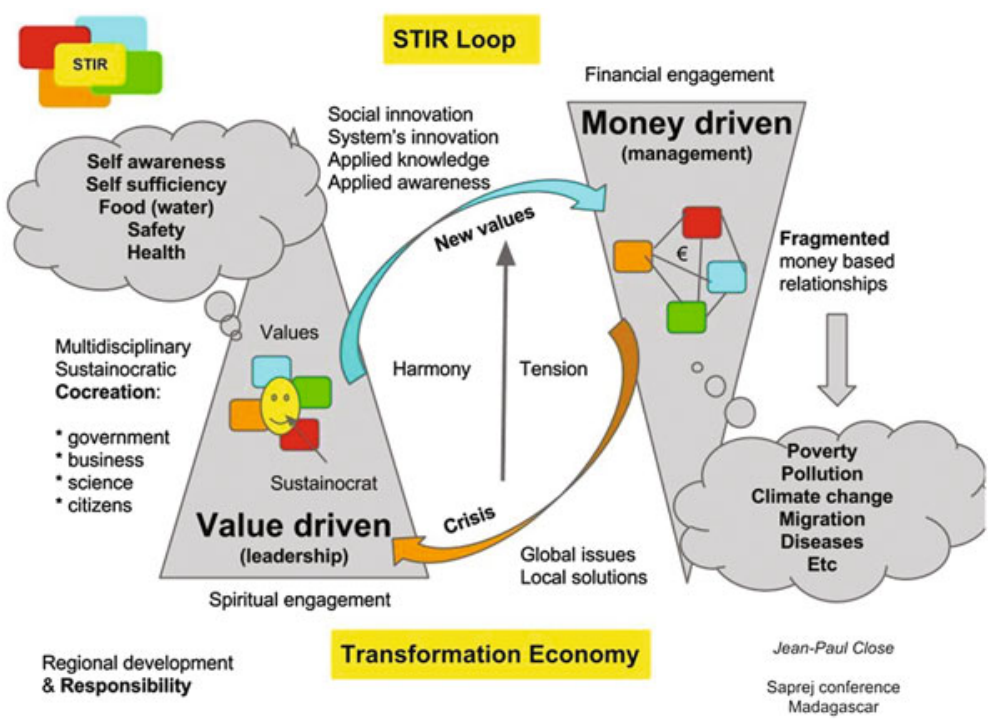

Fig. 4.1 The STIR loop starts with awareness when tension becomes too large (Money driven $=$ welfare- and Value-driven $=$ Wellbeing)

the STIR Academy of the STIR Foundation for educational purposes and implementation worldwide.

However, one loop around alone does not win a battle for the human species, as human complexities continue to challenge our harmony with ourselves and our environment. The fact that the loop now exists and has proven itself means that it can be applied as often as necessary to reduce our vulnerability while benefitting from both the values created and the new economic cycles it announces.

Key in starting the STIR loop is the generally felt need for change, the measurable "tension" that provokes awareness development and the start of the loop. Instead of waiting for the chaos that can collapse financial, societal and even biological systems, one accepts the invitation to introduce multidisciplinary change. STIR always uses core natural human values to define the issue and the higher purpose. In the case of AiREAS, this was clearly defined by "regional air quality, human health and regional dynamics." The reason why partners are attracted and relate to the issue is up to them, and so is the diversity of reciprocity obtained by participating.

By defining and accepting the key human values that need to be protected and enhanced to assure a harmonic society and an ecological relationship, the process for deciding to address the issues when they are in jeopardy is no longer a democratic one. It becomes a leadership issue that can be executed at any time, and when necessary, without having to wait for general elections or budget rounds. The working procedure of AiREAS applies when awareness unites the right disciplines (Fig. 4.2). 
Fig. 4.2 The AiREAS workflow from freedom to structured project processes
Workingprocedure

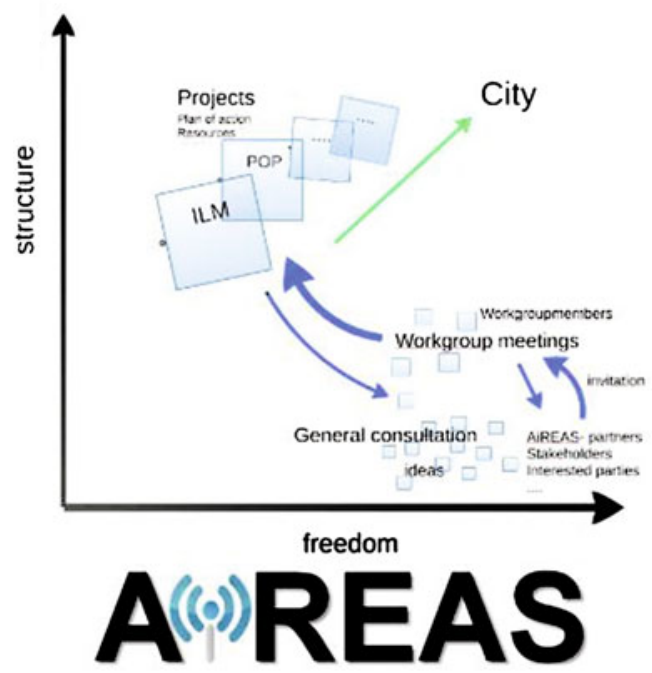

\subsubsection{The Workflow in AiREAS}

The workflow, once the loop is started and captured in a name (s.a. AiREAS), has three steps:

\section{Stet 1: Relating democratic freedom to the higher purpose}

The leading motivation in AiREAS is the higher purpose of co-creating a healthy city, using air quality, human health and regional dynamics as points of measurable reference. Anyone, member or non-member of the cooperation, can propose initiatives that contribute to the mission. In the case of the ILM development, for instance, the suggestion came from the city's councilor. The idea to set up AiREAS in the first place had come from a civilian. Twice a year, AiREAS gets together to simply gather and interpret ideas. When the AiREAS group accepts that the idea, or the suggestion, is promising enough for the mission, the next step is initiated. A simple rule for step 1 applies to all members:

\section{Whatever you can do alone, you do alone. Whatever part of the mission is too complex,} requiring the involvement of the others, is done together.

This simple rule avoids potential misuse of the co-creative capacity of AiREAS or the development of competing interests between the members and the group. Initiatives taken on by the AiREAS group are therefore always compliant to the higher purpose of local wellbeing development and the multidisciplinary, result-driven process of the group. Every step that is completed, such as the availability of the ILM, provides a new set of instruments for the next steps, in 
which any new organization can be involved. Every new step always starts with an empty table again. The loops that were completed generate trust in the process and proof of principle to those who were not convinced enough to participate in the first rounds but will do so for the next.

\section{Step 2: Workgroups are formed}

The idea or co-creation proposition now needs to be worked out into a project. A workgroup is formed with those people, partners, members and institutions that wish to participate, protecting at all times the balanced configuration of a sustainocratic venture (government, business, civilians and scientists). During the workgroup encounters, the project is worked out in detail with all the elements needed, including the individually talented or specialized involvement of each participant, their particular responsibility, the expected results of the project and the financial requirements. Decisions are made on each aspect, including the impact on the city, the involvement and stimulus of the city's population, and the source and structuring of the funding.

During this phase, there is complex negotiation so as to make everything fit, from practicalities to formalizing commitments. The latter is a challenge on its own, because the co-creative participative effort of each of the partners is done from their own perspective of self-interest, often strongly coloured by their speculative welfare origins. The commitment needs to be tied to backing from their individual institutions. Even if a manager, a top executive or key politician is enthusiastic about the AiREAS mission in which he/she got engaged, the backing of the institution they represent needs to be engaged as well. In practice, during the encounters, we first relate to the human being at the table and the commitment to human values from a personal perspective. Only after establishing the importance of the steps to be taken does the professional contribution and authority become relevant.

In many cases, the institution is governed by the old fragmented principle of economy of growth (business and scientific research centers) or political confinements (city government), not the immediate backing for value-driven change for measureable wellbeing that expects an investment in time and talent. The economy of growth (welfare) argument is overcome by the promise to present the project involvement as a potential authentic driver of innovation, with new global growth potential through the traditional transaction economy. Not many potential partners understand this while focusing on short term survival and risk avoidance. They see AiREAS first as a potential customer to sell products to, instead of a societal R\&D in which unique values are co-created, tested and proven for the world market using their products and innovative capacity. Those who do understand create a self-selecting process between the interest in participating and the final formalization of the commitment.

A simple formula is applied here:

Membership is free of charge, not free of commitment.

In every new AiREAS project, the entire process of choice and commitment starts again. The fact that we have gone through the process already once before is a 
positive reference for subsequent cycles. Once committed to the results of the workgroup, the third step can begin. Partners repeatedly commit time after time, project upon project, determining through self-leadership how far they want to go. Without projects, AiREAS ceases to exist, showing that it is not just a self-sustaining initiative, but a value-driven movement. AiREAS depends on the need to create local healthy environments and measureable wellbeing through the willingness of partners to take responsibility together by defining projects. The driving force is often the sustainocrat who maintains the focus on the higher purpose and develops a group's cohesion by introducing challenging encounters.

AiREAS has no resources of its own other than its mission, its bonding way of working and the quality of the commitment of the participating partners. No contracts are involved; just the strength of a result-driven purpose and trust, making the venture unique in the world.

\section{Stet 3: Project execution}

When everything is clear, funding and commitments confirmed, and expected results defined, the team is ready to bring the project into execution. Steps 1 and 2 require interaction at the executive level where responsibility can be taken directly in committing to a process. Step 3 can be delegated to personnel of the participating institutions.

The mix of people involved is unique and interesting. We see civilians participating free of charge out of personal interest for a healthy living environment. Or they develop entrepreneurial initiatives around the wellbeing mission which they test in the AiREAS network. There are self-employed professionals linking large institutions with fragmented specializations to the project's complexity through the budgeted platform. And we see well-paid professionals from big institutions bringing in their expertise and a large company's potential. Civil servants facilitate the activities in the city and often defend the use of public tax money as part of the financial commitment. All the participants have their own uniquely different reciprocity expectations in the project and still complement each other effectively in the value-driven process.

Reciprocity is not just expressed in money, but also in the field of knowledge development, measurable healthy city and personal health development, worldwide product and concept expansion potential, political and social recognition, validation, participation, celebration, team ownership, visibility, etc.

\subsubsection{Financial Routine in AiREAS}

We come from a world structure in which everything is predefined in financial terms before initiating a process. This has proven to be a highly ineffective way of working, creating a lot of unnecessary bureaucracy and fragmented interests, consuming debt before values are created, if they are created at all. The process of 
AiREAS (and any other sustainocratic venture) is exactly opposite. We start with an empty table, without any means, just an abstract, holistic higher purpose for creating human wellness, with partners and whatever means that may be available from society all involved in a result-driven process. No one in AiREAS is paid to be present or to participate. Everyone is invited to trust one's own potential, talent and reciprocal interests in the process.

This is an extremely difficult process in which to initiate people. Many talented self-employed people, for instance, cannot spend two years in a value-driven process with the risk of "no go" without the allocation of compensating funds. They are mostly in short term survival mode in the still dominant world of welfare and trade, and so need to commit only to part time or even wait until the process is close to being completed before agreeing to a "go." The local self-employed are not interested in global expansion and expect their contribution to be expressed in direct local reciprocity. Bigger organizations do have the breadth but find themselves emerged in the market-driven pressure of volume and short term results, often in crisis-managed reorganizations. A middle way is to try to define projects that are complex enough for multidisciplinary co-creation while small enough for a faster throughput. Or we can define steps in between as predefined milestones. For the local contributions a special reciprocal value system can be considered.

This value-driven commitment, therefore, has tended towards a self-selecting nature of participating talents and institutions. The consequence of working with a higher purpose based on a global humanitarian or environmental issue is that any innovative idea is welcome. People educated in the field of budgeted financial economics tend to feel submerged in a process they don't understand when entering AiREAS. Everything seems to happen at the same time, requiring each participant to experience awareness breakthroughs. Everyone undergoes a learning curve. Interestingly, a lot of projects can appear and develop at the same time in all kinds of fields related to health, city dynamics or air quality. And every project has its own unique composition of participants.

\subsubsection{Confidence Based Interaction}

How fast can a complex, multidisciplinary project be organized? That all depends on the level of awareness, commitment and confidence in the participating members. The ILM was extremely complex, and required intense scientific, technological and political interaction in a time of financial crisis and organizational uncertainties for all corporate members.

To keep the group together, delicate interaction was needed that regularly reconfirmed commitment all the way up to the final allocation of the funds for step 3 to take off. This process has also delivered a lot of new insight into and knowledge about value- and result-driven processes in multidisciplinary human complexity. The mix of human and institutional behaviour in a string theory environment of commitment became a field of experience of its own that not 
Fig. 4.3 AiREAS partners commit to this column of values

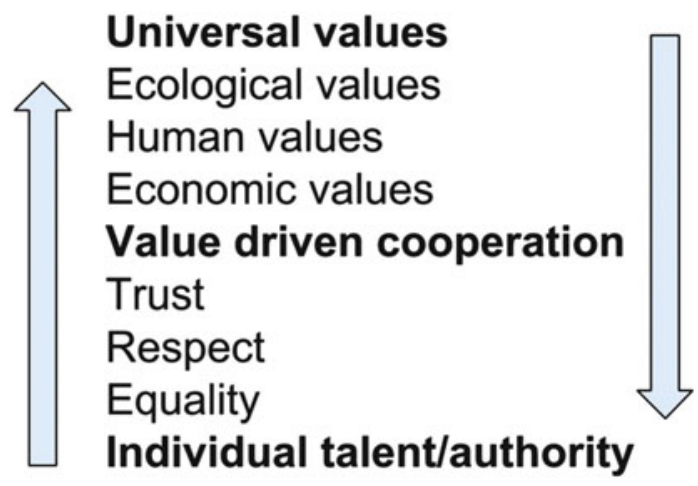

Column of values

Sustainocracy - Close 2012

everyone understood, especially newcomers to the groups. This was also captured in the City of Tomorrow's STIR Academy for expansion into the world.

The column of values defined in the City of Tomorrow, and referred to by Marco van Lochem in his introductory note, was put into practice in AiREAS. It reads as follows (Fig. 4.3).

The financial backing of the project was not process-driven but rather result-driven. The investment of the first "Sustainocrats" (Jean-Paul and Marco) was their own in time and effort for the start-up years. This was necessary to assure their independence from money-driven control mechanisms and decision-making and their ability to steer processes out of the old paradigm. They had to try to sustain themselves in the old money-driven reality and find time to coordinate the value-driven processes through steps 1 and 2 up to step 3 of AiREAS. This was not easy, but determination and trust in the mission made it worth their while. Initiation of step 3 can hence be seen as a milestone for the sustainocrat, while it is an operational kick-off for the partners.

The financial structure is therefore as follows:

Steps 1 and 2: AiREAS uses the infrastructure and facilities of the participating partners. No costs are involved for AiREAS while usage of space and catering is seen as representation costs for the partner. No one receives any payment of fees in this entire process.

Step 3: $\quad$ Means are allocated, including actual financial means, as opposed to all the resources that partners may provide (buildings, infrastructure, personnel, etc.) which are investments as well. Money is a means, just like talent, authority, commitment, technology, knowledge, etc. They all are an investment in the concrete value creation processes defined in the project.

For the sustainocrat, the start of a project is a milestone that is rewarded through a percentage in the financials of the project. For the other participants, it is a kick-off 
to co-create a new set of values with financial backing for their efforts. The following financial formula is used for $100 \%$ of the financial commitment (real money allocated to the project).

\begin{tabular}{l|l|l}
\hline $100 \%$ & $\begin{array}{l}\text { Project } \\
\text { value }<500.000 \\
\text { euro (\%) }\end{array}$ & $\begin{array}{l}\text { Project } \\
\text { value }>500.000 \\
\text { euro (\%) }\end{array}$ \\
\hline AiREAS overhead (sustainocrats) & 10 & 5 \\
\hline $\begin{array}{l}\text { Education, group network support (new Local } \\
\text { AiREAS) and representation }\end{array}$ & 10 & 5 \\
\hline Operational capital (result driven) & 80 & 90 \\
\hline
\end{tabular}

There is always a natural grey area between the switchover moment of $<=>500 \mathrm{~K} €$. This is dealt with transparently within the dynamics of each project, and with the participants settling somewhere between 10 and $5 \%$. The same formula applies when the operational capital is divided over operational groups that have their own overhead which is managed by self-employed individuals who act as sustainocrats in their subgroup, linking their activities with the others. This way of working is not meant as a hierarchy but as uniformity in equality within the operational processes. Within the allocation of operational capital, differences may apply because of the participation of all kinds of organizations, each of whom have their own operational reality. Sometimes we see a sustainocrat who takes on certain operational tasks too. This is done when the experimental phase requires the effort and knowledge they can provide or when no other professional can be found to do the job.

"Result-driven project operations" means that partners are not charging input based on hours and material invested but on expected and measurable outcome. Partners are expected to do their part in the commitment. The values that are created have worldwide potential but only when the results have been finalized and made visible. For the business partners, the economic profit is not in the co-creation itself, which can be seen as a societal multidisciplinary R\&D, but in the expansion of what has been created together. It is, hence, an investment. Since local government and citizens are the direct beneficiaries of the co-creation, it is logical that they participate in the labor and financial backing. But they cannot be treated like a cash cow. Equality remains important and money cannot be dominant, a position always reserved for the results, measured against the higher purpose. It is the task of the sustainocrats to keep that framework centered among all the participants.

\subsubsection{October 2013 General AiREAS Participants Meeting}

With the availability of the ILM in September, the finalization of phase 1 is coming into sight. A general partner and participant meeting was called for to determine the 
Table 4.1 New potential projects

\begin{tabular}{l|l|l|l}
\hline Number & $\begin{array}{l}\text { Proposed } \\
\text { by }\end{array}$ & Proposition & Group decision \\
\hline 1 & $\begin{array}{l}\text { Dr. Eric } \\
\text { de Groot }\end{array}$ & $\begin{array}{l}\text { Research project of 4000 local citizens } \\
\text { on health in relation to air quality }\end{array}$ & Yes \\
\hline 2 & Ben Nas & $\begin{array}{l}\text { Involve city quarter FRE2SH activities } \\
\text { (another City of Tomorrow initiative) in } \\
\text { AiREAS }\end{array}$ & $\begin{array}{l}\text { Yes (maybe combined } \\
\text { with 1) }\end{array}$ \\
\hline 3 & $\begin{array}{l}\text { Marco } \\
\text { van } \\
\text { Lochem }\end{array}$ & $\begin{array}{l}\text { Co-create an App for mobile phones to } \\
\text { show air pollution status in real time }\end{array}$ & Yes \\
\hline 4 & $\begin{array}{l}\text { Nicolette } \\
\text { Meeder }\end{array}$ & $\begin{array}{l}\text { Investigate behavioral issues } \\
\text { (criminality, mental health, etc.) in } \\
\text { relation to air pollution }\end{array}$ & $\begin{array}{l}\text { No (maybe combined } \\
\text { with TU/e research } \\
\text { project) }\end{array}$ \\
\hline 5 & $\begin{array}{l}\text { Marco } \\
\text { van } \\
\text { Lochem }\end{array}$ & $\begin{array}{l}\text { Integrate ILM with traffic management } \\
\text { system }\end{array}$ & $\begin{array}{l}\text { Maybe if positioned as } \\
\text { health co-creation, not } \\
\text { commercial }\end{array}$ \\
\hline 6 & $\begin{array}{l}\text { Doctor's } \\
\text { post }\end{array}$ & $\begin{array}{l}\text { Establish an AiREAS research office in } \\
\text { the new city center development of } \\
\text { Strijp-S together with doctor's post }\end{array}$ & $\begin{array}{l}\text { No, due to absence } \\
\text { of proposer }\end{array}$ \\
\hline 7 & $\begin{array}{l}\text { STIR } \\
\text { Academy }\end{array}$ & $\begin{array}{l}\text { Entrepreneurial push around ILM } \\
\text { Nome to address this }\end{array}$ \\
\hline
\end{tabular}

next steps for AiREAS in the healthy city project. Seven suggestions were proposed by members (Table 4.1).

At the time of finalization of this analysis, several of the proposed actions have reached project status, showing that the STIR loop is being continued. At the same time, new challenges have been introduced into the finalization of the first phase, ones that we deal with in this manuscript. We needed to ask ourselves the following questions:

- When is phase 1 (ILM) finalized? This question became relevant because new initiatives placed new demands on the ILM. The enthusiasm of the development team is considerable, and one needs very little to pick up new requirements and include them in the technological plans. The problem is that AiREAS has neither resources nor funding of its own. The cooperation is purpose-driven through projects that produce measurable steps towards a "healthy city." Phase 1 was budgeted without those new issues. Any new proposition first needs to go through the three steps to get to financial backing. However, when a proposition is made for many people, it has already become part of an expected reality that they include in their talks. The ending of the ILM became postponed as phase 1 was continuously renewed with new requirements but without additional financial commitments. We needed to break through this impasse and determine the finalization of ILM phase 1, allowing for the start of ILM phase 2, or, alternatively, find indefinite funding. The latter was unlikely, even though we had proposed creating a start-up fund with government money as a type of loan. 
This had not worked out yet. So the best way to deal with this was to close phase 1 properly, account for it, and open up workgroup discussions for the next phases.

- How do we interpret the data of the working ILM and deal with feedback and new requests coming from the new project ideas? Some parts of the ILM infrastructure need to remain fixed for medium term scientific research, while new scientific plans and feedback information suggest a remodeling of the network. Static versus dynamic becomes a point of potential friction. The installation of the ILM is could be considered a technological milestone, but for the scientists involved, it was only a starting point. They need a variety of data from multiple years to enable true interpretation for their research. On the other hand, the progressive nature of AiREAS towards a healthy city brings in new knowledge and views that demand the dynamic adjustment of the infrastructure. The handshake between the two extremes has fostered a continuous discussion.

- How to finance new projects? The Eindhoven city council and the Province invested in the ILM and its basic scientific research. Any new ideas needed to be funded themselves, and could not simply rely on the purse of the city. AiREAS had defined a royalty structure and also tried to link with innovative impulses that were generated by its open data, but these cyclic economies needed time to develop.

While all these issues were at hand, we started to look at the data provided by the ILM when it was released from Validation and Calibration in December 2013.

\subsubsection{Interpreting the ILM Data}

When the ILM became operational in September 2013, the only way to access the data was through an IP address from a database (see Chap. 3). This may be a valid procedure for professional users in the participating institutions, but for the general public, additional visualization was needed. Key in the initiation of AiREAS was the desire to involve citizens in their own healthy city development and the inherent responsibilities. AiREAS was, after all, a citizen's initiative. But how do you communicate in such a way that citizens react positively to innovation and their behavior? In the introduction to this manuscript, we have already referred to the levels of awareness of individual people and the lack of awareness of the masses. People today resonate to the hum of consumer- and money-based welfare. How can we open their minds to committing to the development of and contribution to their own wellbeing? How do we establish a society that opens up to change without fear of the unknown, strengthened through a sense of responsibility that starts with one's own perception of reality? Or can it be done in a different way? Making visible the invisible had opened up a whole array of research issues.

For instance: General, money-driven attitudes produce fears that if the pollution in a region becomes common knowledge, the prices of the houses might drop. This 
would justify avoiding openness in AiREAS communication. Other concerned people suggested that individuals with lung or heart problems would seek remuneration when scientific proof is made available about the effects of pollution on their health, especially when it becomes known that the State has reacted with reluctance in regard to their overall responsibility for pollution patterns while blindly focusing on economic growth. Comparisons were made with the tobacco industry and smoking, including the multibillion dollar claims against these enterprises.

\subsubsection{The Transition}

A new transition of governance became apparent. In the past, the prevailing social economic culture for welfare tended to avoid openness about certain environmental or humanitarian issues for fear of critics, financial drawbacks and economic growth impediments. The new tendency towards total openness and stimulating, self-regulating, wellbeing-based practice in the city can be seen as a breakthrough. This transformation in attitude was not supported everywhere, and there were certainly many who looked at the development with doubt and fear. But open data on the internet had already shown that cover-up strategies would never last and, in the end, would become a bigger political hazard than openness. After all, openness not only invites criticism but also encourages the taking of mutual responsibility for solutions, with all their innovative spin-offs. Eindhoven took the lead by accepting AiREAS as an instrument for change, but at the same time, needed to accept that it had to change itself too.

\subsubsection{Communication}

Being a multidisciplinary organization with civilian participation, the issue of communication became a serious new area of experimentation. We could distinguish three areas of attention right from day 1 of the operational working of the ILM:

1. Reading and interpretation of the near real time data

2. Communication with the city's population

3. Avenues of use for what we learned about the pollution patterns.

By the time we finalize this manuscript (June 2015), we will have 18 months of experience with these three points. It is an ongoing process that will get richer and richer as we proceed. As already stated, we need to define milestones. The ILM was designed to "make visible the invisible." At this stage, we can state safely that this mission is accomplished. The next step is to determine what to do with what we see 
that we couldn't see before. We must go step by step through these three points. This represents a powerful learning curve.

\subsubsection{Reading and Interpreting the Near Real Time Data}

The ILM had been designed by technology- and science-driven experts. You have already seen, at the end of Chap. 3, a list of new scientific research activities that were organized around the ILM. Technicians and researchers may have the knowledge to work with the raw data streams coming from an IP address, but the town's citizens, the AiREAS Sustainocrats and many others involved would need another human interface to visualize the air quality status. This was something we did not know yet and were about to find out. Such tools were not yet available for use.

\section{ECN Tool}

New Year and fireworks

The first event that triggered our curiosity was New Year's Eve, 2013/2014. ECN had the only self-made tools for looking at the real time and historical data. The first real time views of pollution of fireworks arose out of our enthusiasm for the potential of the ILM system. It was also the very first time that we got insight into the behavior of Ultrafine Particles (UFP) measured in 5 locations (Fig. 4.4).

The experience was tremendously positive, but instantly gave rise to the need for processed facilities and new information feeds for usage not just by ECN, but by AiREAS in general. The internal tooling of ECN was a first step but was not yet a tool for public use or for usage throughout AiREAS.

Fig. 4.4 New Year fireworks 2013/2014 UFP

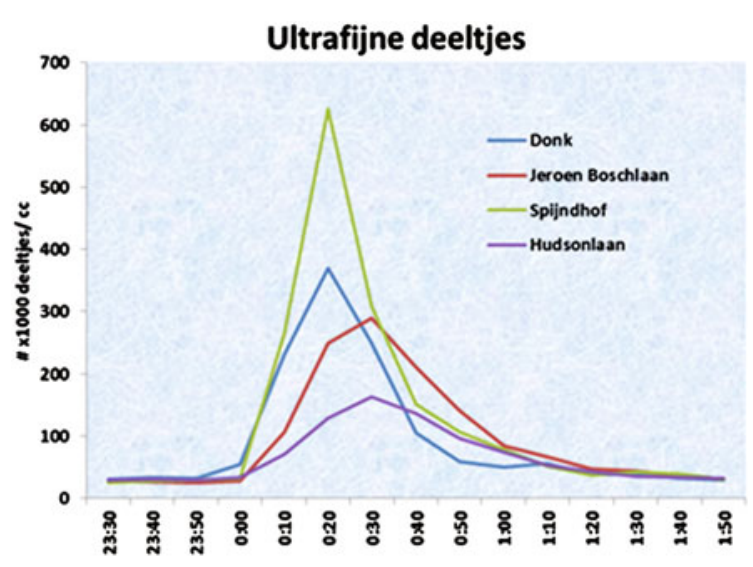




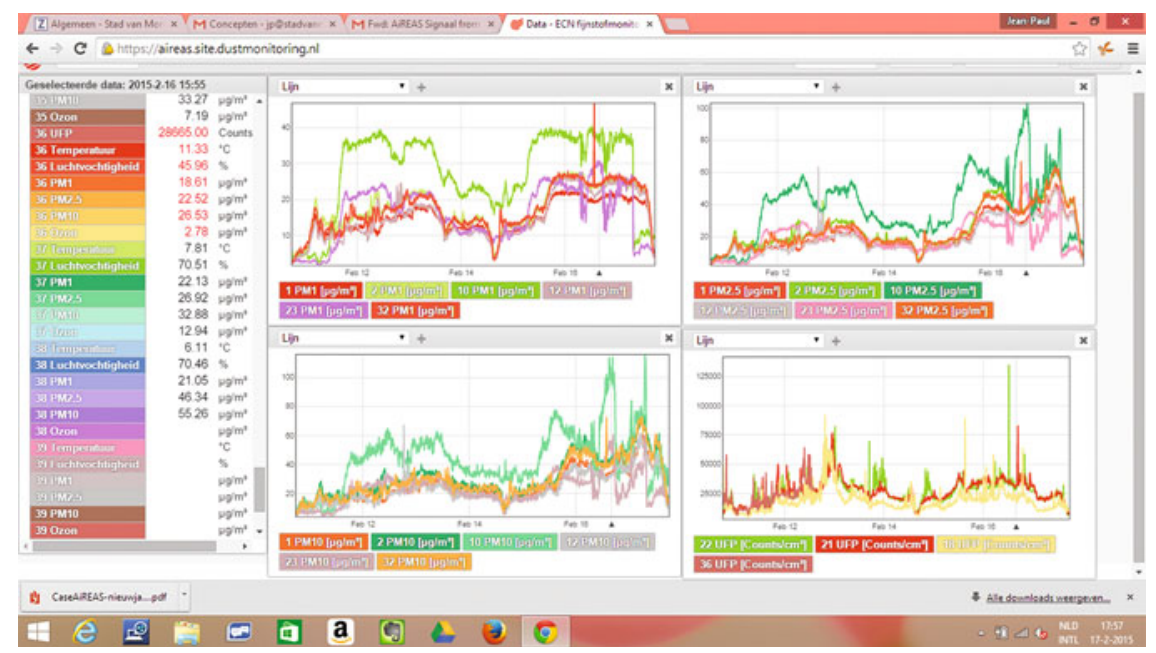

Fig. 4.5 A screenshot of the ECN tool

ECN suggested offering its internal tool for testing purposes to the AiREAS organization. The tool offered historical insight into the data and a dynamic graphical display option of data from each Airbox combined according to type of measured particle size or visualized in a mapped version (Fig. 4.5).

The tool was made available for limited use within the AiREAS partner and management structure to enable analysis of visualized data. This was indeed useful, especially when observations were required of high pollution suspects, such as the firework peaks. But the tool did not trigger curiosity or real time event monitoring.

\section{The Imtech App}

During the October 2013 meeting, Marco van Lochem successfully suggested developing an App for mobile phone usage. The normal routine would have been to go through the three steps of "the way things work at AiREAS". Then, the App would have received co-creation attention and a budget for development. To our surprise, Imtech had already taken on the challenge internally as a production of its own, and in June 2014, the App was presented as a teaser in a limited test edition (Fig. 4.6).

It was the App from Imtech that allowed for instant monitoring of the ILM network. The color code used by the App signified moments of intensified pollution by changing from green to orange and red. The border values for changing the colors were more or less in line with the norms used in the Netherlands, but by no means yet within an agreement. That was not possible because we had no idea yet what to agree to. The tool became a fundamental citizen's observatory that triggered curiosity in real time when colors changed. One simply had to develop the habit of 
Fig. 4.6 A screenshot of the Imtech App (now Axians)

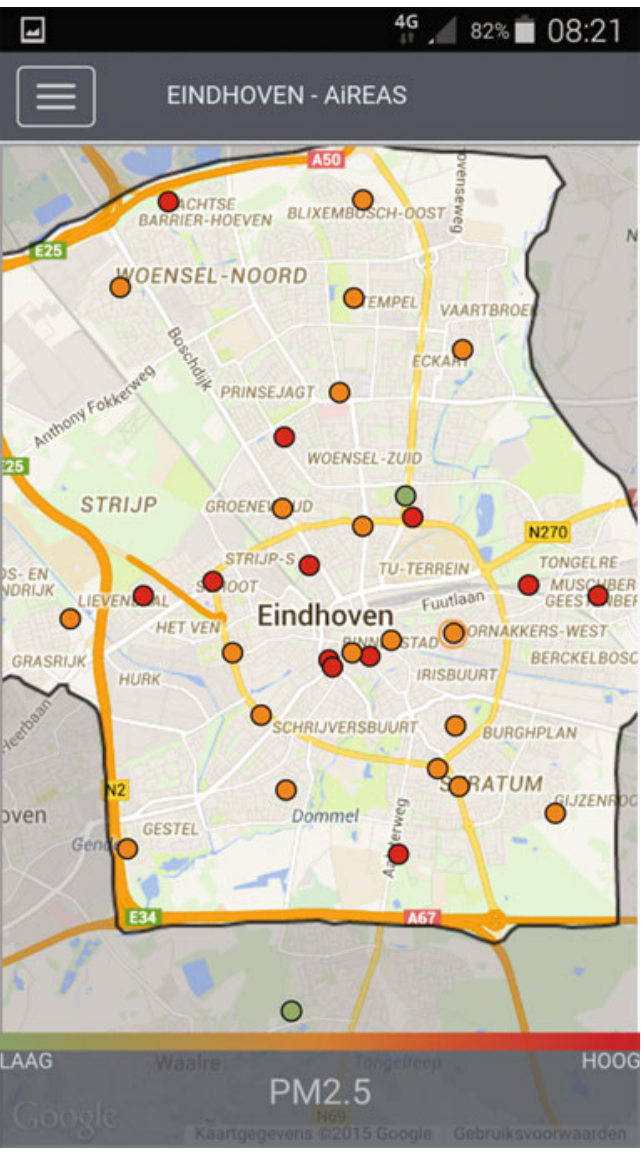

opening the App once in a while to check the status of the network. Then, someone who wanted to go into more depth of interpretation or analysis could take the ECN tool and work out some explanation.

The App initially worked with limitations and remained in the experimental phase. The first experiences were negative due to start-up installation problems and the incompleteness of the information supply. No pollution events had occurred yet that could possibly justify the App. A comparison was made with the air quality App of the RIVM (Ministry of Health). This App did not really contribute to awareness either nor did it trigger curiosity. Imtech claimed an investment of $70 €$ without AiREAS's coverage or perspective of reciprocity. It was frustrating for them that the effort had not gotten the enthusiastic backing that they felt it deserved. At the same time, it became clear that certain partners were still inclined to let their welfare mentality take over when they saw a chance. For most people involved, it became a learning process to distinguish between the two paradigms and make rational choices about when to apply one or the other. 
Things changed drastically for the App when one summer morning, the first APP tester, co-founder Jean-Paul Close, looked at it and saw for the first time, to his surprise, a drastic change in coloring of the Airboxes. Nearly the entire city had turned orange and red. It was July 21, 2014. This called for further investigation. The entire team was notified about the phenomena and instant curiosity inspired people to analyse the situation in order to produce a preliminary interpretation and explanation for the curious event. A combination of massive BBQ'ing in the city, no wind, warm sunshine and high levels of humidity, had caused a peak of chemical reactions to occur in the air. These produced nausea, sickness and even death in certain people with lung problems.

This was the first time that an event in real time had been detected and opened as case for instant analysis with open feedback to the city via the blog, social media and the local news media. Without the App to trigger curiosity, this event could have passed unnoticed, ending up in the statistical averages without the possibility of cross-referencing it with real time environmental observations and the other key sensors available to us: our eyes, noses, ears, etc.

Instantly, the App gained status of key importance to AiREAS, to the satisfaction of Imtech, even though it had not yet been incorporated into a project with financial backing for development. The experience was positive, and discussion started on how to improve the App with the feedback and experiences obtained. This discussion, of course, may develop into and AiREAS project status, possibly with positioning on the EU scale with intended funding from H2020 unless Axians decides to keep the development and deployment to themselves.

The issue now arises that we probably would not have been able to develop as many insights as we have had Imtech (now Axians) ${ }^{1}$ not made the decision to develop the App. The project-driven route would have eventually satisfied the financial backing of the early development, but this would have taken time in a setting in which no one knew what to expect. This time and awareness was gained thanks to the proactive attitude of Imtech/Axians, strengthening our ability for instant insights and the overall positioning of AiREAS in the early field of citizen's observatories. This too was an important lesson learned, and we trust that Axians will eventually be compensated by the effort.

\section{Casus Collection}

With the Imtech/Axians App, the ECN tool and the lively city equipped with the ILM, a whole series of observations were registered and documented during those 18 months. It was decided that every case would be described and shared among the teams for further elaboration. As of the writing of this document, the following cases have been registered:

\footnotetext{
${ }^{1}$ At the end of 2014, portions of the multinational Imtech were taken over by Vinci Energies in Paris and renamed Axians.
} 
- Firework peaks, 2014 and 2015 (two years, two different weather types)

The culture of fireworks to celebrate the New Year has been shown to be highly polluting, especially in the ultrafine dust (UFP) spectrum.

\section{- Summer $B B Q$ peak}

The combination of mass usage of barbecues with specific weather conditions displayed very surprising results and interpretations. The local hospital helped with the observation that similar situations had occurred in operation chambers when the burning technique of closing wounds would produce fumes that reacted with pollution from the street and high OZONE levels. It also produced nausea among the OC personnel.

\section{- Liberation day with 300 war vehicles (no peak)}

Every year, Eindhoven celebrates its liberation days. In 2014, the celebration had an extra dimension since it had been 70 years since the city had been freed by the allied forces. A huge festival was organized, with over 300 old time war vehicles. One would expect that such a massive parade of heavy trucks moving through the city would produce high levels of pollution. To our surprise, nothing of that was detected. Also, the noise levels of the engines of those trucks seemed to be much less than those in their modern counterparts. This suggests that the technology in World War II was much more sustainable than what followed it.

- Light route (peak)

In an additional celebration of the liberation, and as a tourist attraction, Eindhoven lives up to its name of the Light City by organizing the Route of Lights, a winding path of various illuminations throughout the city. This event lasts three weeks. The pollution peaks that we missed during Liberation Day were clearly visible during the Route of Lights. That part of town was highly polluted for the entire three weeks.

\section{- Torch event-Christmas peak}

Another popular event around Christmas is the Torch Light Parade. Thousands of citizens join together to carry torches along a specific route. This stands as a call for solidarity and social cohesion. This event was also clearly spotted in the measurements.

\section{- Different behavior UFP compared to $P M>1$}

On various occasions, different behavior was detected between ultrafine particles and those of a larger size. UFP are generally produced by local events while anything larger tends to affect the entire city. The dispersion, particle behavior and reactions seem fundamentally different from the other type of particles. 


\section{- Inversion-weather}

At a certain stage, high levels of pollution were detected for no apparent reason. Investigation led us to a weather phenomenon called "inversion". A cold air front presses on top of a hot layer below, compressing the air, including its pollution. The opposite occurs when the front has passed.

- Possible strange situation Mauritsstraat (2 Airboxes nearby show totally different values)

Why would two ILM stations located at a short distance from each other show fundamentally different values? Is this due to technical reasons or are local circumstances playing a role?

\section{- Possible agricultural cause of high peaks of pollution}

In March 2015, a sudden peak of pollution affected Europe entirely to the extent that big cities like Paris took remedial measures to close the city to certain traffic. No apparent cause could be detected until someone suggested that seasonal agricultural preparations of the land could be behind the peak.

These cases were collected and compared with similar situations over the years. Meanwhile, the cases have been presented to:

- the operational kernel of AiREAS to see what measures are possible to reduce the pollution

- the entrepreneurial community of Eindhoven to see if solutions can be found through technological innovations

- the scientific community to enhance our scientific insights and produce new projects for investigation and development of knowledge

- the public through open communication to trigger social innovation and awareness.

\subsubsection{Communication with the Citizens}

Let us jump back to December 2013. The positive decision to work out applications for mobile phones had not yet materialized into a project or a funding agreement. There was still discussion on what such an application should look like. Should we produce the end result as an APP or produce an API, an interface to which APPs could be related? The parallel decision by Imtech to produce an initial APP was an interesting case for seeing how such communication would work. But the App was not available yet by the end of 2013 .

The only people who could monitor the network at this stage were ECN and those few partners that could deal with the direct data access link. There was, however, one place where the data was going to be displayed. This was the AiREAS website. The site development had been agreed upon as part of the first phase.

www.aireas.com 


\section{AiREAS Website}

Who could imagine that the relative simplicity of setting up a website would become, in regards to communication, such a virtual tower of Babel? Right from the formal kick-off of AiREAS phase 1 (making the invisible visible) in October 2012, we tried to establish a communication team that could experiment with communication from a "persuasive" point of view. In the book "Sustainocracy, the new democracy," which describes Jean-Paul Close's process of awareness all the way up to the founding of AiREAS with Marco van Lochem and the formal kickoff at the city hall of Eindhoven in October 2012, the concept of "Burger-BAGE" is introduced. It is a concept for civilian involvement and alliance with the eco-system for "sustainable human progress," including health and air quality.

"Burger" means "civilian" and BAGE is an acronym of the following Dutch words, explained in English:

- "Bewustwording"-Awareness development

- "Aanvaarding"-Acceptance of new responsibility

- "Gedrag"-A change in behavior

- "Erkenning"-Reward for change of conduct.

The website was to experiment with these insights and produce awareness first. It would establish a relationship with the local citizens that would trigger the acceptance of responsibilities for the development of wellbeing. This type of dynamic in the website gave rise to many disputes and diversity in points of view. The building and maintenance of the website had not been budgeted for such complexity, and the people involved in the development were all small-scale entrepreneurs who could produce a simple website but refused to co-create the necessary communication skills through experimentation with new techniques and feedback. Since this type of awareness-driven persuasive communication is new, we could not find people with the sort of skills needed to be involved in the project. This meant that we had to develop the experience ourselves through trial and error.

Two elements of experience were crucial for the subsequent development of AiREAS:

\section{The website is an information tool, not a communication tool}

The website was recognized as a semi-static tool for supplying information, but not a system for communication. Communication requires human value-driven interaction between the sender and receiver, with feedback interpretation and experience development around the potential triggers of acceptance and societal change. A website is more of an online brochure in the world of welfare and trade. Social interaction is much more personal and a group process around wellbeing-based cohesion demands totally different tools and settings.

\footnotetext{
${ }^{2}$ Close (2012)—Sustainocractie, de nieuwe democratie-MultiLibris.
} 


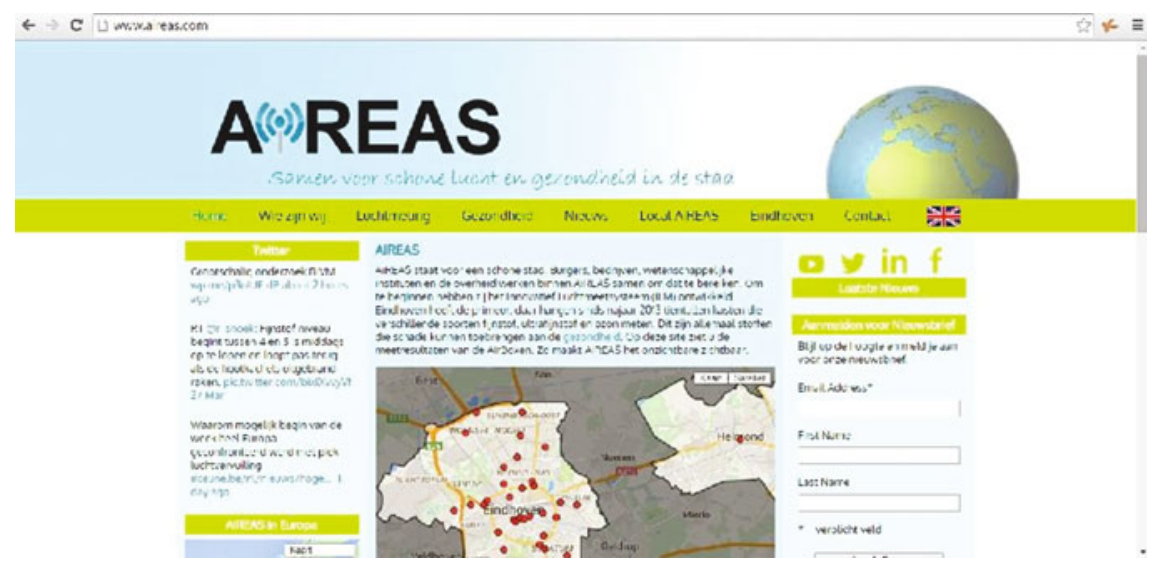

Fig. 4.7 The AiREAS website

With this insight in mind, the disputes were resolved, and after going through four different communication teams, we finally found rest and peace by placing the website's hosting and maintenance in the hands of a low cost support organization (Fig. 4.7).

The site provides information about AiREAS and shows a Google map of Eindhoven, with all the ILM measurement spots. Clicking on any spot displays the latest measurement data. Citizens can get insight in real time, but no historical information is provided (yet). Various citizens started using the information on the website by registering by hand every $10 \mathrm{~min}$ the relevant information for their own use. It was a start.

2. Awareness is not the only factor for triggering action, as the majority of people are mere followers

An AiREAS encounter in 2012 dedicated to civilian participation was hosted by the University of Technology at Eindhoven with the participation of Dr. Jaap Ham. Ham specializes in the psychological research of effects of technology on the behavior of human beings. When Jean-Paul Close explained Burger-BAGE, Dr. Ham stated immediately, to everyone's surprise: "No awareness! People are flock members, they follow the mainstream." This simple contribution had a major impact on the development of AiREAS. An example was used to sustain Ham's comment.

In the pursuit of energy transition, a lot of costly (welfare mentality) marketing was done to convince homeowners to install solar panels on their houses. There was no success until a young entrepreneur asked his house-owning uncle if he could place solar panels on his roof. The uncle agreed, and even convinced a neighbor to do the same. Within a few months, the entire street had solar panels. 
With these two fundamental insights it had become clear that communication was to become an essential part of AiREAS. We needed to differentiate between the provision of static information via a website or press release, the marketing type of sales-oriented communication and the dynamics of communicating experiences, best practice and positive examples of behavioral change and innovation to trigger the population to follow. The early adapters ("me first") in every population may be acting from awareness and the desire to contribute to "a better world," but the mainstream population will only follow and produce a change of culture if they get acquainted with those changes, identify with the results by wanting to be a "me too" 3 part of it and can gain easy access.

The website issue had been solved and positioned, but now we needed to address the dynamics of true communication and its influencing potential. A new line of experimentation appeared, instantly influencing the preparations of the AiREAS POP (phase 2) and the way we communicated openly with and about our findings.

\section{The Blog Became Our Dynamic Tool}

Jean-Paul Close and the City of Tomorrow awareness programs had already developed a lot of experience in blogging.

- Jean-Paul's blog (in English): 5000 visitors average per year from 95 countries (mainly NL and USA)

- City of Tomorrow blog (in Dutch): 18,000 visitors average per year from over 40 countries, mainly NL, B, USA, Ge.

AiREAS activities had so far been shown and documented through the City of Tomorrow blog, along with all the other activities of the STIR Foundation. It was decided to set up a blog for AiREAS itself:

https://aireas.wordpress.com (Dutch)

While the blog was certainly open to anyone interested, it was written in Dutch specifically to address the community in Eindhoven. It was set up in 2013 and its number of visits has continued to grow, now averaging 4000 per year. The blog is directly linked to Twitter, LinkedIn and Facebook (Fig. 4.8).

An important effect of blogging and tweeting is the direct interaction with the local media, who pick up news items for processing in their written editions. Since the operational installation of the ILM and the direct, real time access to air quality information, we have received regular attention from the media when unique, interesting and curious insights have been discovered and shared through the blog.

\footnotetext{
3"Me1 (me first) and Me2 (me too)" positioning aspects as one of the 5 keys for success by Jean-Paul Close (guide for future market leaders-2005).
} 


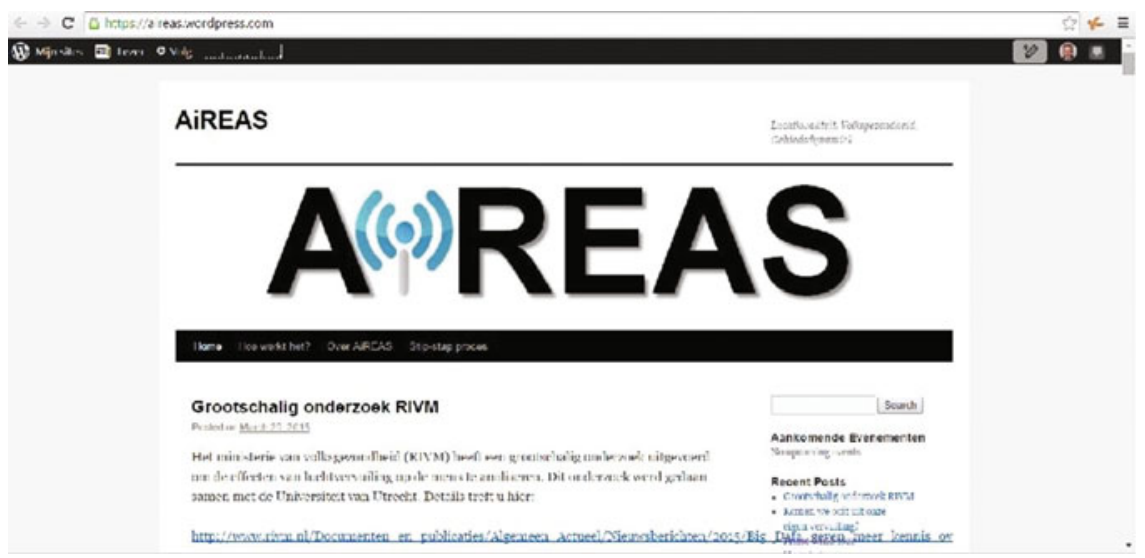

Fig. 4.8 The first AiREAS blog

Filming Progress via YouTube

The STIR Foundation was already in the habit of trying to visualize its initiatives through film. It was difficult enough to get participants into such simple processes as a congress, an encounter or a kick-off. Depicting our activities on film at least gave us the possibility of sharing the insights with a larger audience or integrating them into other forms of communication.

People don't tend to resonate with a new paradigm solely through words. Worldviews are simply too far apart. A video often explains much more and becomes a lasting document of a process. Recording critical events also helps as an educational tool when similar situations happen in new areas of attention. It provides people with a feeling of trust, as well as a sense of belonging, when they start to experiment in different ways with the new reality.

Here are some AiREAS recordings on YouTube:

The AiREAS concept in English: https:/www.youtube.com/watch?v=iyxo6St YMw4

The same in Spanish: https://www.youtube.com/watch?v=LudujXawOCc

The APP demonstrated: https://www.youtube.com/watch?v=MBk5aVvj1wc

AiREAS real time data demo: https://www.youtube.com/watch?v=Jxig4 YxTF6w

Fireworks Impact 2014/2015 (In Dutch):

https://www.youtube.com/watch?v=PpvHHDGGR8Y

The local TV news item on the hanging of the first Airboxes: (In Dutch) https://www.youtube.com/watch?v=2BwznuCGtwU

The complexity of getting to a commitment: (In Dutch)

https://www.youtube.com/watch?v=KxnuJz5y66E\&list=PLBZBIkixHEidkOSv CbhJowtwJppiSU8OQ\&index $=1$ 


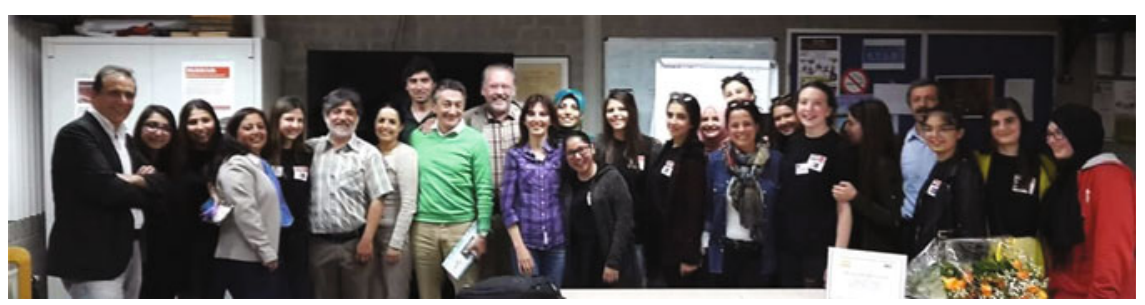

Fig. 4.9 Students from Turkey help to explain the AiREAS concept to the Turkish community residents in Eindhoven

The formal announcement: (In Dutch) https://www.youtube.com/watch?v=sw8v Be-A9i0

The STIR HUB using AiREAS as an example: (In English):

https://www.youtube.com/watch?v=cCPyOgc7S1I

\section{Citizen Encounters}

Using all the knowledge that we had gradually visualized, we organized numerous citizen encounters.

With Milieudefensie: A partner organization, Brabant Milieudefensie, is an NGO that also deals with air quality. We participated in each other's events to stimulate attention on air quality. More than 3000 signatures were collected in the interest of influencing city council elections.

With STIR Academy: This other STIR Foundation initiative organizes evening lectures and entrepreneurial encounters to stimulate the development of social and technological innovation. The STIR Academy experiments with the AiREAS coin, a value system that is given to local people who excel in their contribution to the field of health in the city. With it, they can follow the education programs of STIR Academy.

STIR Academy also became a European channel through the videoconferencing HUB platform and the Erasmus+ student exchange program (Fig. 4.9).

Through Business Partners: The "Dutch Leadership Trail"4 visited AiREAS with a group of 20 CEOs. Axians organized the Internet of Things encounter on Eindhoven's High Tech Campus using AiREAS as a high tech example. AiREAS was selected as one of the potential finalists of the VINCI rewards. AiREAS has been invited to various encounters to speak about its views and method of working.

With FRE2SH: With this other STIR City of Tomorrow cooperative, dedicated to local quality productivity, tourism and self-sufficiency, new bicycle routes were developed. These routes connect points of interest to tell the story of sustainable

\footnotetext{
${ }^{4}$ The Dutch Leadership trail is an initiative organized by Camiel van Damme and Pierre Mellegers.
} 


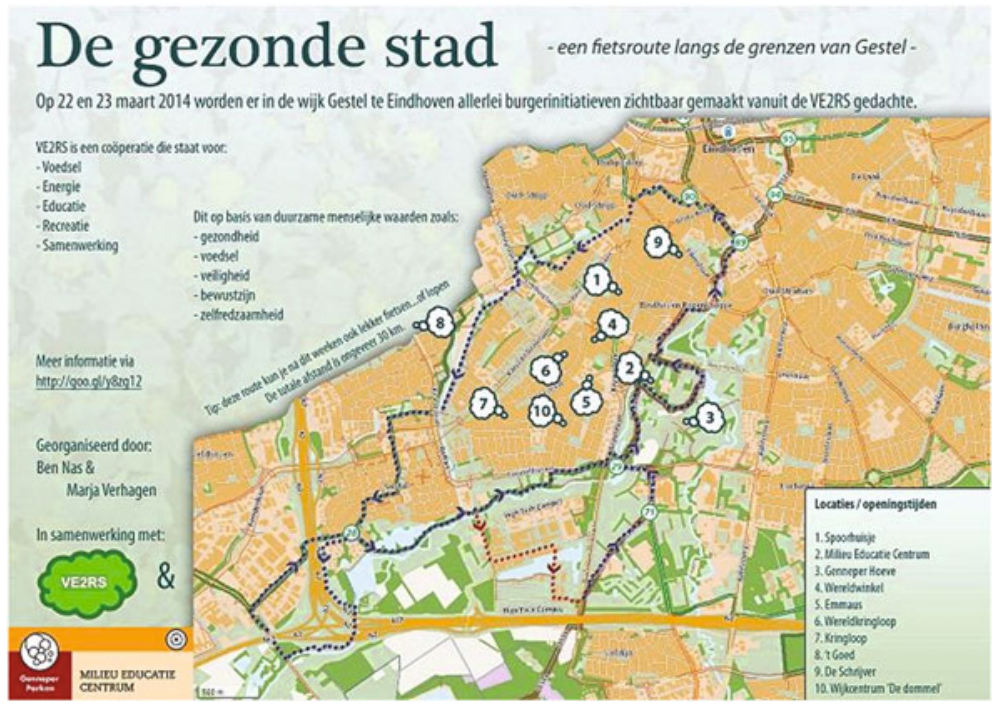

Fig. 4.10 The healthy city bicycle trail co-created with FRE2SH

human progress, varying from historical landmarks to good examples of entrepreneurship in value-driven processes, and even the site of an Airbox.

Air quality, innovation, co-creation, civilian participation and tourism based on health and quality of life have become instruments to link regions in the Netherlands and Europe through the Triple " $i$ " (inspiration, innovation and implementation) platform of STIR Academy (Fig. 4.10).

This continuous interaction is slowly changing the way everyone looks at the city and its air quality. The tenor of the majority of the feedback we have received is one of worry. Many people feel helpless and don't really know how to address the issue. The question arises for AiREAS as to what we can do with the data and public/private commitment to make a difference.

\subsubsection{What to Do with What We Learn About Pollution Patterns}

When we look at the accumulated values around the public/private commitment to air quality and human health, we can already conclude the following:

- We can detect air pollution events in near real time and respond with observations to complete the casus. We can then use these specific cases to reflect and determine actions throughout the AiREAS partnership team.

- We can share this information with the public to stimulate:

- social innovation

- technological innovation 
The data is shared among the AiREAS partners, which include the local government, scientists, business enterprises and civilians. Each may use the data for their own specific interests.

It has become clear that pollution is not just the byproduct of traffic and industry, but that many events and behavior-related issues in the city contribute as well. Scientists eventually may provide insight into what is healthy and what is not from an air quality and climate change point of view. Cultures have been built around lighting fires and burning things for human comfort and pleasure. Some of these issues can be overcome by introducing technological innovations, but many will require cultural modification around how we deal with our environment and our wellbeing. That is probably the most difficult issue to deal with.

Persuasive communication ${ }^{5}$ has become a topic of discussion and an instrument to practice with. Persuasiveness is needed to achieve entrepreneurial backing through the development of innovations that make sense. These contributions will also use marketing channels as a way to help expand the movement. This type of communication has already become an area of scientific research: "How can we use technology to influence people?" In the public area of "safety in traffic," we already use technology extensively, but in all the other areas of key human wellbeing, as defined in Sustainocracy, we do not. Persuasion is sometimes perceived negatively, as it suggests "manipulation." When looking at our current society, manipulated as it is around capitalist hierarchies and dependencies, persuasion in the cause of awareness can be seen as a confrontation between interests: those who require blind submission and those who require aware participants.

$36 \%$ of the population in Eindhoven is worried about air pollution, but only $0.1 \%$ actively takes action to do something about it. How do we increase that percentage of action? We have come up with various experimental trajectories that will be the subjects of new publications as they progress, representing new phases in our approach. They can be summarized into three key areas of attention:

1. Combining data from different sources, e.g., health, lifestyle, traffic, trees, weather and air quality

2. Further stimulating the innovation markets for new products and services, as well as social innovation patterns

3. Studying best practice in terms of persuasive communication techniques for mass involvement.

\section{Spreading of AiREAS Values}

The unique way of doing things at AiREAS and its higher purpose are recognized by all partners and made visible through publications, public presentations and representation in other cities. Breda was the second city to adopt the AiREAS

\footnotetext{
${ }^{5}$ Stiff, James Brian, and Paul A. Mongeau. Persuasive communication. Guilford press, 2003.
} 
method by adding certain specific elements of its own, such as the effects of heat stress on the wellbeing of the city population.

The general partner assembly of AiREAS agreed in January 2014 that the cooperative had proven specific unique values to the world that can be expanded globally at this stage:

1. The multidisciplinary, sustainocratic, value-driven methodology of AiREAS

2. The experience and knowledge obtained in working with this method and the tension it sometimes produces with other paradigms

3. The ILM measurement system, with its important scientific contributions for modelling, data analysis and cooperative interpretation of multiple data feeds

4. The proof that wellbeing-based awareness generates new innovations and even business development for the welfare markets.

All this together is referred to as AiREAS phase 1. It can be adopted by other cities and regions as a self-contained package representing a lot of expertise and insight that no longer needs to be developed locally. With this basic phase 1 being readily available, any new city or region can concentrate on bringing in its own social, historical, cultural and demographic elements to produce authentic and unique spinoffs for the local community and market, as well as the international market.

\subsubsection{Benchmarking and Referencing Our Practical Ideologies}

While writing this analysis, we also began referencing our practical work with theories that had evolved elsewhere. We were already using many drawings in our text from the hand of co-founder Jean-Paul Close. Others have made drawing and models as well, and at this stage, it may be interesting to look at the contributions of Peter Senge ${ }^{6}$ and Otto Scharmer ${ }^{7}$ (best known for Theory U) who introduced the Ego to Eco matrix on the site of the Presencing Institute. It shows four levels of awareness that are similar to the Dabrowski layers of positive disintegration introduced in Chap. 1 (Table 1.1). The most interesting contribution of this matrix is in its presentation of this awareness at individual, group, institutional and global system levels (Fig. 4.11).

When we look at this matrix, we see the evolution of the AiREAS story all the way up to putting the level 4 'Awareness-based collective action' into practice. The key to Sustainocracy is that it can position any community-based society today

\footnotetext{
${ }^{6}$ Kofman, Fred, and Peter M. Senge. "Communities of commitment: The heart of learning organizations." Organizational Dynamics 22.2 (1993): 5-23.

${ }^{7}$ Scharmer, Claus Otto. "Theory U: Leading from the emerging future." A Social Technology of Freedom (working title) (2007).
} 


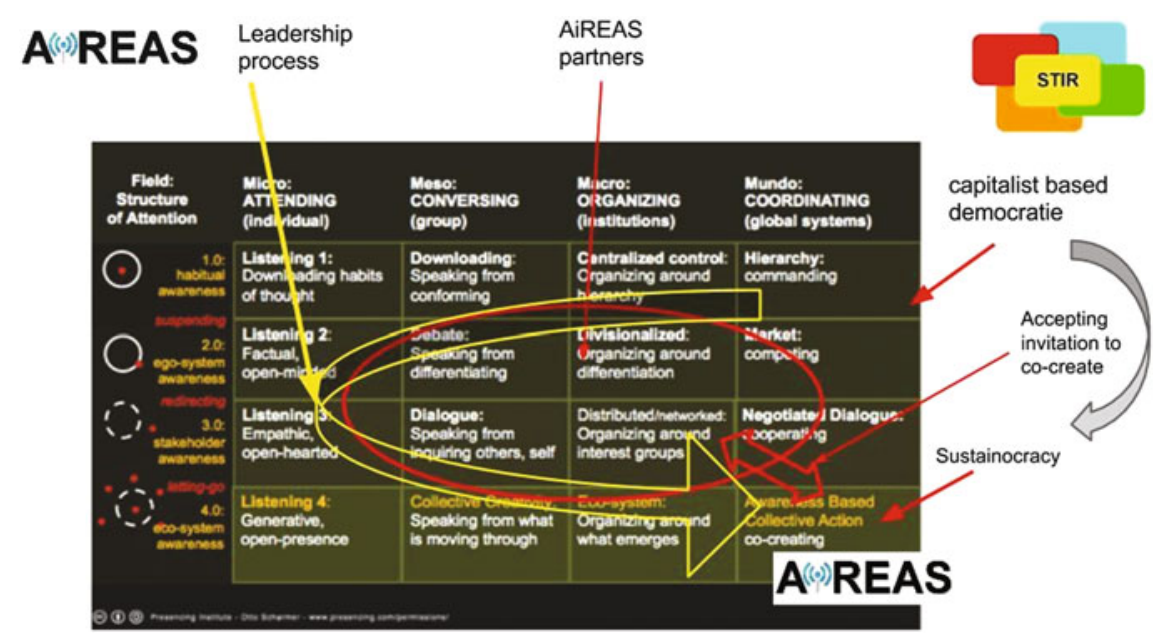

Fig. 4.11 The complexity and process of transformation (matrix is courtesy of the Presencing Institute, USA)

within that particular matrix quadrant. Community leadership is representative of commonly accepted key human values, as explained in Sustainocracy, through proven awareness and commitment. Individuals, institutions and entire community cultures may find themselves on any of the four levels of awareness. Those who emphasise eco-awareness are willing to consider participating in the co-creation platform of AiREAS. Some people have that level of personal empathy, but may work in institutions or cultures that do not. They either have enough authority to start down a transformation path with the institution, perhaps using participation in AiREAS as a guiding principle, or they don't have that authority and decide not to join the effort.

When comparing this with the publications of Dr. Kazimierz Dabrowski and his views on positive disintegration, we see that the layers are very similar to what the Presencing Institute uses in its matrix (Fig. 4.12).

It became clear that local platforms such as AiREAS depend very much on human beings who have reached the required level of awareness, combined with the level of professional authority to accept partnership in a coalition. Newcomers that lack the insight and awareness tend to disturb the process in the AiREAS setting until they break through or leave the group. Many people and institutions passed through AiREAS in this first phase, trying to connect from their level of awareness, but only those at level 3 and higher remained.

At the same time, we see the system's overall awareness develop within the old hierarchy, slowly letting go of the past while the AiREAS proof of principle began to prove itself as viable alternative. Meanwhile, a lot of longstanding impediments revealed themselves, typical of an ego- and competitive-led paradigm but useless and problematic for an eco-driven co-creative reality. Some of these impediments 


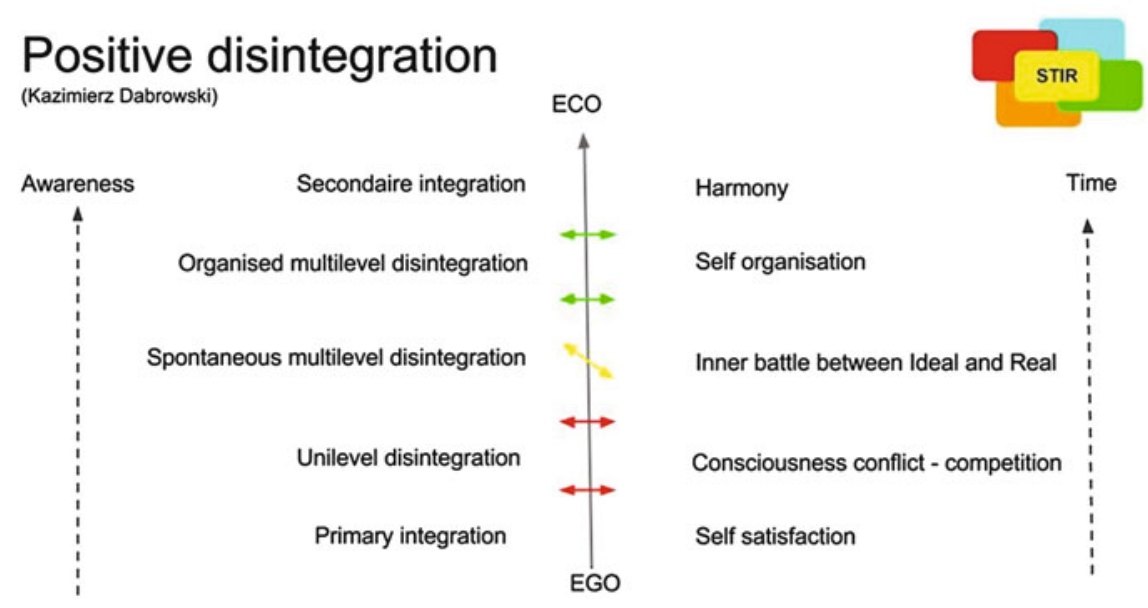

Fig. 4.12 These levels of awareness prove key to multidisciplinary co-creation

could be found in our constitutional development of rules and laws. The AiREAS process showed a lot of self-inflicted societal obstacles that needed to be addressed in order to make the new paradigm comfortably operational. Indeed, AiREAS was successful in making much more visible, often issues that previously had been considered normal and remained undisputed. Now, we could show a path forward, making clear the obstacles that needed to be removed. All the values that can be created need a level of freedom to come into existence. Connecting this at a later stage back into the world of transaction-based economics through royalties makes it worth the old system's while to facilitate the new paradigm and solve the obstacle issues.

\subsubsection{The Royalty System}

The human values-driven productivity of a Local AiREAS (city) provides the world with unique knowledge-based innovations that can be extended throughout the traditional commercial world. Since all innovations generated in an AiREAS cooperative contain the intellectual property of all participating members, a royalty is included in the global expansion of the values. The royalties are managed by Global AiREAS and revert back to the region of the Local AiREAS where the values were co-created. This way, the Local AiREAS is stimulated to keep innovating and calibrating its efforts to its own health and air quality development, as documented proof of principle for the world market.

The value creation dynamics and royalty scheme applied in AiREAS is referred to as the Pyramid Paradigm and was introduced into 21st century business development by Jean-Paul Close in 2007 (Fig. 4.13). 


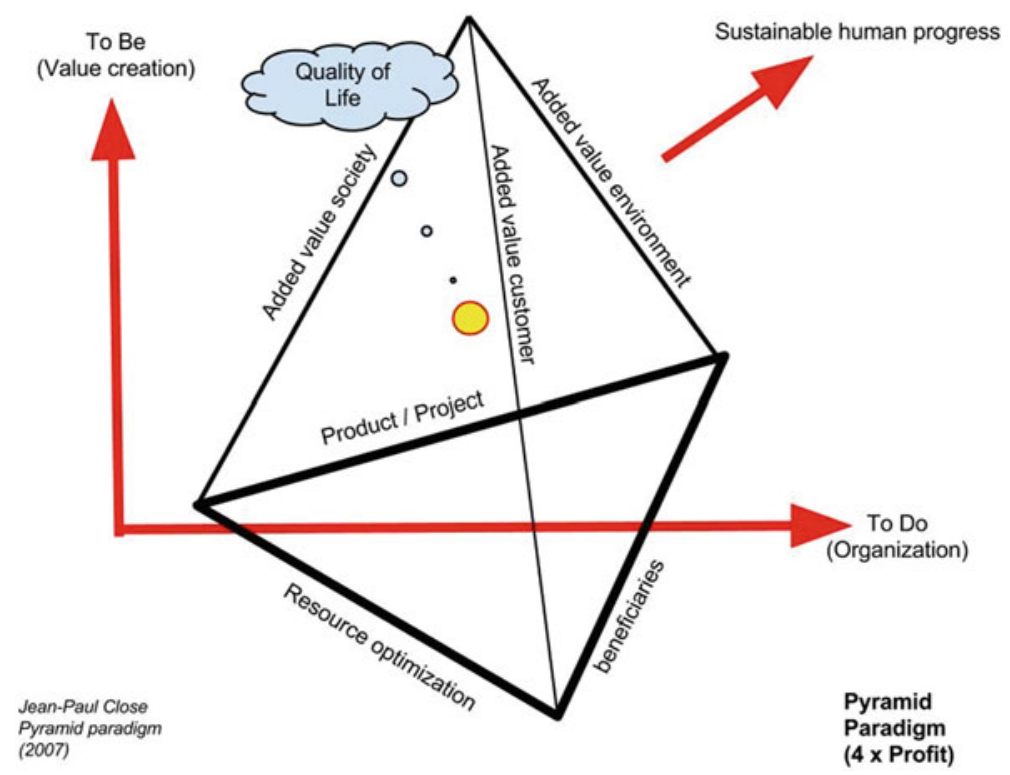

Fig. 4.13 The value-driven pyramid paradigm for business

\subsubsection{Some of the Transformative Issues}

During the evolution of AiREAS in Eindhoven, certain transformative issues were encountered. They proved that AiREAS was visualizing many more invisible things than just air pollution. Here, we list a few examples:

- The cooperative that cannot be: AiREAS is value-driven cooperation in which all partners engage for the higher purpose of co-creating healthy cities. A formal cooperative in Holland within the old paradigm can, however, only be legally set up to defend and grow the material interests of its members. All values co-created in AiREAS can, of course, be related back to economics once they have proven themselves, but this is a secondary consequence. The primary cooperative issue is the production of improved regional health and air quality. The secondary issue is connecting the values that were co-created to the trade system through the partners. It is highly debatable that a co-creation might be considered "illegal" by the reigning system. This demands a serious review of our systems of law and probably even our constitution, or at least the way we implement it in different paradigms.

- Government cannot be a member: The co-creation of a healthy city in a multidisciplinary setting cannot be envisaged without the participation of the city governance that controls tax collection, spending and infrastructure. But officially, the city government, in the present day role of constitutional executive, cannot be a member of the consortium if it is also co-financing it. In our 
current legal setting of money-dependent hierarchies, the financial partner has a control function on the expenditure of the means. It cannot control itself. In AiREAS Eindhoven, an exception was made, but this, of course, needs to be formalized within our legal systems. As soon as a Local AiREAS produces its own innovation fund with the royalties obtained, then the problem disappears. The transformative issue is one that changes the government's position from that of a regionally dominant contractor into a facilitating partner for regional development.

- Tax authority: Initially, the tax authority did not accept AiREAS as a business enterprise that can reclaim value-added taxes. "You are an end user of what you purchase in the healthy city context and, hence, not liable to reclaim the taxes." Our arguments that our healthy city approach is a public/private Research and Development infrastructure for further expansion to the rest of the world, as well as a structure for triggering royalty-based entrepreneurial spin-offs, only landed when we produced our first invoices. Meanwhile, the tax authority had frozen the tax payback, causing a $21 \%$ gap in the AiREAS phase 1 budget. It was eventually solved through Marco's administrative thoroughness and tenacity, but the transformative issue is needed to establish a solid case for eventual changes in the tax policies for genuine Sustainocratic functions. Recognizing the harmonization effects of the "transformation economy" as a basis for new economic growth impulses should do the trick. It is just a matter of time and further proof of concept for it to become part of the societal mainstream and its operational structures.

- Business partners: The business partners that committed to the AiREAS processes had to get used to the project and its result-driven way of working in the context of multidisciplinary wellbeing. AiREAS has no other initial means than those made available by the partners. Values can only be recognized and documented when they have proven themselves as measurable results within the "healthy city" context. AiREAS is hence not a customer, but a connecting instrument between means and goals to achieve a desired result. Planning and commitment are essential for building trust among the partners. If a commercially-oriented organization begins to ask for more money halfway through a project, then the overall partner relationship is upset and so is the execution of the project. Business partners had to get used to rewarding themselves through the global expansion potential of value creation, not trying to enrich themselves through the co-creation effort and the group's investment. This had a transformative effect. Some new age entrepreneurs came in directly from the value-driven perspective. Old-fashioned enterprises often disappeared or required adjustment to fit in.

- Civilian partners: Civilians in our city are used to dealing with a dominant, hierarchical government that makes decisions for the citizens. One is used to asking permission for everything related to governance. This permission-based culture of caretaking is broken when the citizens begin taking responsibility themselves, without the need to ask for permission. Permission-based systems are bureaucratic and base their decisions on the old rules of a money-driven 
system. Responsibility within the common context of a "healthy city" needs no permission, since every initiative or innovation is a welcome contribution to the town.

- Government follows civilian leadership: When City of Tomorrow kicked off in 2009, we wanted to define "sustainability," resulting in our definition of "sustainable human progress," including civilian responsibilities. The 2009 Government in Eindhoven still managed the city from the perspectives of economic accessibility and growth, with innovation platforms directed at the world's mass markets, not self-usage or local proof of principle. In 2010, new elections allowed the city the chance to work on "sustainability, applied innovation and civilian participation." City of Tomorrow had already started the AiREAS "healthy city" project, to which the councilor personally connected and committed. In 2014, further new elections resulted in a city council prepared to commit to the "healthy city," while City of Tomorrow and AiREAS were already expanding worldwide. In Eindhoven, AiREAS had started to develop the eco-system of local self-sufficiency by combining City and Rural activities through FRE2SH. Gradually, local governance follows the calibration of activities based on new ethical values and insights for sustainable progress. For the individual, it is a choice; for a complex institution such as a city government, it is a transformative process based on a combination of defining policy leadership and working from civilian precedents.

- Reward system for wellbeing: Our financial systems are geared towards financial trade and welfare development. Wellbeing development is not rewarded. The question as to "why someone tightening screws in a factory is rewarded with money and a woman investing her time and effort in raising her children, the members of the next generation, is not?" resonated in AiREAS. People that have access to labor often have to commute between work and home using polluting mechanisms. And they get paid for it. Those who try to solve the issues through awareness-based co-creation are only compensated when products or services appear that help remediate the problem, not for their awareness-based social innovation or behavioral changes. It is difficult to understand the functioning of the reward system in a polluting context and the lack of it in a context of responsibility. We created an AiREAS coin as a catalyst for value creation. Its use could be compared with a farmer who puts in a lot of effort to make his crops grow successfully and harvests abundantly. If the farmer's efforts relate one to one to the harvest, then no additional value system is needed, the harvest is his/her value. When, however, the input is provided by hundreds of people who then have to wait some time before the harvest becomes available for sharing, a coin system helps as a reminder of the individual contribution as a key to sharing what has been achieved. The AiREAS coin does not compete with the Euro, it enhances it by developing values for enlargement and reciprocity for those who invested in it. Meanwhile, the coins could be invested locally in education, network encounters and local productivity-sharing, making the remaining coins even more valuable in their local circuit. 
- Lawful solidarity and ethics: Citizens are lawfully obligated to sustain their local governance and system through the constitution. Laws have been adopted that demand people express their solidarity through tax and insurance systems. Ethical conflicts arise when the current system shows itself to be responsible for the pollution that it tries to remediate by taxing the same system's parameters, demanding more and more. The ethical conflict exists within the definition of ethics itself. Is it ethical to maintain lawful solidarity with an economic system that has proven itself to have reached a destructive level? Or do ethics mean commitment to ecological and anthropological harmony with our surroundings and the transformative challenge of adjusting the human system's dynamics through the evolution of awareness?

- Wellbeing and welfare: Gradually, the duality of a trade- and wellbeing-based system at a regional level could be balanced. Wellbeing would create innovations that welfare could expand worldwide. The transformation economy of change interacts proactively with the transaction economy of growth. By placing the emphasis on wellbeing-based change and not on growth, a new regional balance between productivity and consumption could be initiated.

\subsubsection{Conclusion}

AiREAS phase 1, making visible the invisible, opened eyes and awareness to much more than just air quality in the city. The entire transformative process of a city community that starts calibrating itself, its behavior and dynamics based on a new set of human and environmental values has become visible through the AiREAS Eindhoven process. Getting to this point has proven to be a warm, valuable and rewarding exercise for everyone. This sounds like an ending, but in reality, it is a milestone representing the beginning of everything. Having made the invisible visible in all its complexity and transformative dynamics, all parties may now find it much easier to interact towards further steps in the permanent healthy city objective. We have provided the living body of the city of Eindhoven with a nervous system and the very first real and artificial intelligence to work with it. This is just a start. Phase 2, the POP ${ }^{8}$ has started. And so have different working groups around key issues such as CalVal (Calibration and Validation in low cost, open access dynamics) and Persuasive Communications (how technology and awareness affects human behavior).

\footnotetext{
${ }^{8} \mathrm{POP}$ (Proof of Principle) research and civilian participation project linking air pollution exposure to human health and lifestyle. This project started in January 2015 with 40 participants. It expects to optimize the complex processes involving many disciplines and up to 11 different databases for cross-referencing and persuasion, to expand it to 4000 citizens in Eindhoven and 4 Million in Europe.
} 


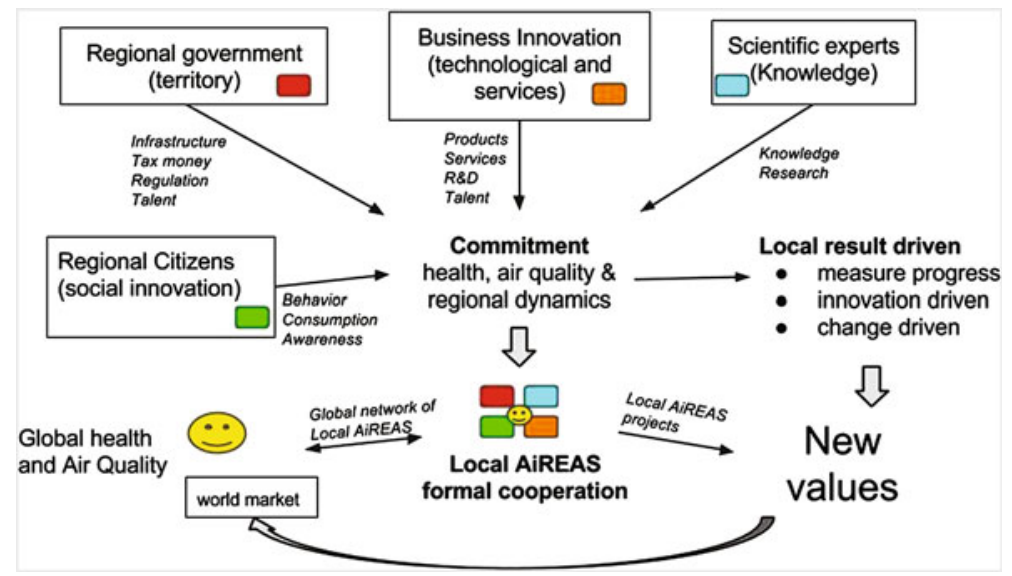

Fig. 4.14 Summarizing the new world of AiREAS

Phase 1 is providing enormous amounts of data for our universities to analyse and generate feedback. The entrepreneurial spinoffs are just a pioneering beginning of much more to come. Eindhoven will transform further and be an inspiring example for the entire world (Fig. 4.14).

I would like to close with a comment by our ICT database specialist and key phase 2 member John Schmeitz: "Everything we do in AiREAS is from the heart. We don't know the specific outcome up front but trust our venture and partners. All the values that appear ultimately reward us all in multiple ways, as they will all the generations to come."

Phase 1 has been successfully completed; phases 2 and 3 are on the way.

The AiREAS team (June 2015).

Open Access This chapter is distributed under the terms of the Creative Commons Attribution-NonCommercial 4.0 International License (http://creativecommons.org/licenses/by-nc/ 4.0/), which permits any noncommercial use, duplication, adaptation, distribution, and reproduction in any medium or format, as long as you give appropriate credit to the original author(s) and the source, a link is provided to the Creative Commons license, and any changes made are indicated. The images or other third party material in this chapter are included in the work's Creative Commons license, unless indicated otherwise in the credit line; if such material is not included in the work's Creative Commons license and the respective action is not permitted by statutory regulation, users will need to obtain permission from the license holder to duplicate, adapt, or reproduce the material. 